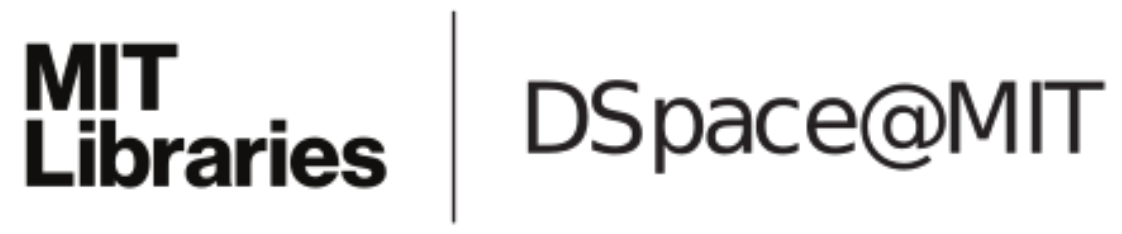

\author{
MIT Open Access Articles
}

Fast and slow responses of Southern Ocean sea surface temperature to SAM in coupled climate models

The MIT Faculty has made this article openly available. Please share how this access benefits you. Your story matters.

Citation: Kostov, Yavor et al. "Fast and Slow Responses of Southern Ocean Sea Surface Temperature to SAM in Coupled Climate Models." Climate Dynamics 48.5-6 (2017): 1595-1609.

As Published: http://dx.doi.org/10.1007/s00382-016-3162-z

Publisher: Springer Berlin Heidelberg

Persistent URL: http://hdl.handle.net/1721.1/108804

Version: Author's final manuscript: final author's manuscript post peer review, without publisher's formatting or copy editing

Terms of use: Creative Commons Attribution-Noncommercial-Share Alike 


\title{
Fast and slow responses of Southern Ocean sea surface temperature to SAM in coupled climate models
}

\author{
Yavor Kostov $^{1,2} \cdot$ John Marshall ${ }^{1} \cdot$ Ute Hausmann $^{1} \cdot$ Kyle C. Armour $^{3}$. \\ David Ferreira $^{4} \cdot$ Marika M. Holland $^{5}$
}

Received: 7 January 2016 / Accepted: 29 April 2016

(C) Springer-Verlag Berlin Heidelberg 2016

\begin{abstract}
We investigate how sea surface temperatures (SSTs) around Antarctica respond to the Southern Annular Mode (SAM) on multiple timescales. To that end we examine the relationship between SAM and SST within unperturbed preindustrial control simulations of coupled general circulation models (GCMs) included in the Climate Modeling Intercomparison Project phase 5 (CMIP5). We develop a technique to extract the response of the Southern Ocean SST $\left(55^{\circ} \mathrm{S}-70^{\circ} \mathrm{S}\right)$ to a hypothetical step increase in the SAM index. We demonstrate that in many GCMs, the expected SST step response function is nonmonotonic in time. Following a shift to a positive SAM anomaly, an initial cooling regime can transition into surface warming around Antarctica. However, there are large differences across the CMIP5 ensemble. In some models the step response function never changes sign and cooling persists, while in other GCMs the SST anomaly crosses over from negative to positive values only 3 years after a step increase in the SAM. This intermodel diversity can be related to
\end{abstract}

Yavor Kostov

yavor@mit.edu; yavor.kostov@physics.ox.ac.uk

1 Department of Earth, Atmospheric, and Planetary Sciences, Massachusetts Institute of Technology, Cambridge, MA 02139, USA

2 Present Address: Clarendon Laboratory, Department of Physics, University of Oxford, Parks Road, Oxford OX1 3PU, UK

3 Department of Atmospheric Sciences, School of Oceanography, University of Washington, Seattle, WA 98195, USA

4 Department of Meteorology, University of Reading, P.O. Box 243, Reading RG6 6BB, UK

5 National Center for Atmospheric Research, Boulder, CO 3090, USA differences in the models' climatological thermal ocean stratification in the region of seasonal sea ice around Antarctica. Exploiting this relationship, we use observational data for the time-mean meridional and vertical temperature gradients to constrain the real Southern Ocean response to SAM on fast and slow timescales.

Keywords Southern Ocean - Southern Annular Mode . Surface westerlies · Atmosphere-ocean interaction . CMIP5

\section{Introduction}

In contrast to the strong global warming trend, the Southern Ocean (SO) has exhibited a gradual decrease in sea surface temperatures (SSTs) over recent decades (Fig. 1; Fan et al. 2014; Armour and Bitz 2016; Armour et al. 2016). The large-scale geographic pattern of warming is related to the climatological background ocean circulation (Marshall et al. 2014, 2015; Armour et al. 2016; Hutchinson et al. 2013, 2015). In the SO region, deep waters, unmodified by greenhouse gas forcing, are upwelled at the surface where they take up heat as the mean wind-driven circulationpartially compensated by the eddy circulation-transports them northward (Marshall et al. 2015; Armour et al. 2016). The background circulation can therefore reduce the rate of surface warming in the SO relative to the rest of the World Ocean. However, this mechanism of passive heat transport is not sufficient to explain the persistent surface cooling trends around Antarctica.

Some studies interpret the pattern of observed Southern Hemisphere SST trends as a response to a poleward shift and strengthening of the surface westerlies. These recent tendencies in the atmospheric circulation resemble 
the positive phase of the Southern Annular Mode (SAM) of natural variability, but they may in fact be a forced response (Thomas et al. 2015), the result of ozone depletion (Thompson and Solomon 2002; Gillett and Thompson 2003; Sigmond et al. 2011; Thompson et al. 2011; Wang et al. 2014). Figure 1 illustrates the synchronous evolution of observed SST and SAM anomalies over the SO. The SST averaged between $55^{\circ} \mathrm{S}$ and $70^{\circ} \mathrm{S}$ is negatively correlated with the SAM index at a lag of 1 year $(R=-0.65)$. Multiple mechanisms have been proposed to explain the relationship between SST trends around Antarctica and poleward intensification of the westerlies.

Many studies conclude that a poleward intensification of the westerlies impacts SO SSTs by changing the ocean circulation (e.g., Hall and Visbeck 2002; Oke and England 2004; Russell et al. 2006; Fyfe et al. 2007; Ciasto and Thompson 2008; Bitz and Polvani 2012; Marshall et al. 2014; Purich et al. 2016). The recent circulation changes have been confirmed by measurements of dissolved passive tracers (Waugh et al. 2013; Waugh 2014). A positive SAM induces anomalous northward Ekman transport in the high latitude region of the Southern Hemisphere (Hall and Visbeck 2002). This gives rise to surface cooling poleward of $50^{\circ} \mathrm{S}$. Ciasto and Thompson (2008) and Sen Gupta and England (2006) propose that the aforementioned oceanic mechanism complements SAM induced changes in the surface heat fluxes, and that both processes act in concert to set the spatial distribution of temperature anomalies around Antarctica.

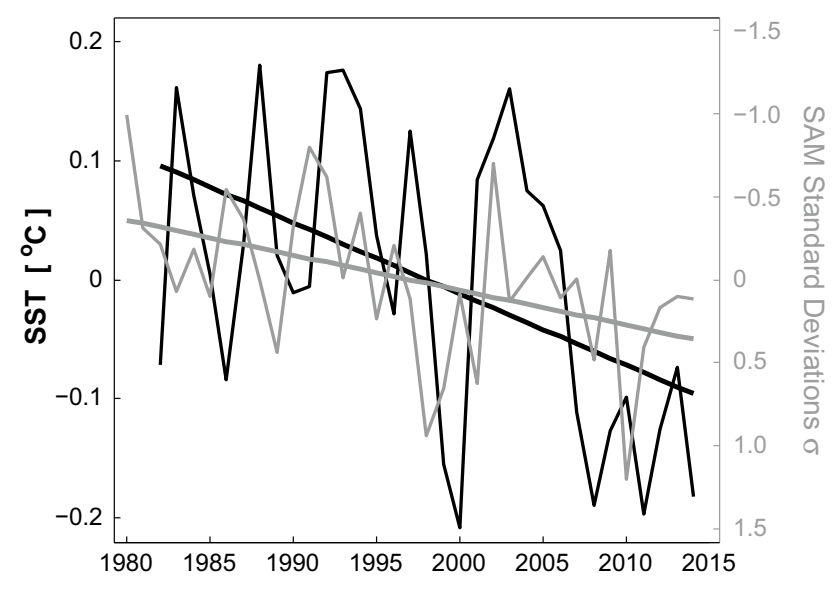

Fig. 1 Shown in black is the 1982-2014 timeseries of SST $\left[{ }^{\circ} \mathrm{C}\right]$ averaged between $55^{\circ} \mathrm{S}$ and $70^{\circ} \mathrm{S}$ based on the NOAA Reynolds Optimum Interpolation (Reynolds et al. 2002). The 1980-2014 timeseries of the annual-mean SAM index based on the ERA Interim reanalysis (Dee et al. 2011) is superimposed in gray. The index is defined as the first principal component of SLP variability south of $20^{\circ} \mathrm{S}$ and is normalized by its standard deviation. Thick straight lines indicate linear trends fitted to each timeseries. Note the reversed scale for the SAM timeseries shown on the right
Meanwhile, Bitz and Polvani (2012) demonstrate that in the coupled CCSM3.5 GCM, an ozone-driven poleward intensification of the westerlies leads to an increase in SSTs throughout the SO. This result implies that changes in the winds cannot account for the observed cooling around Antarctica and may even have the opposite effect. Bitz and Polvani (2012) explain that poleward intensification by itself can lead to a positive SST response via anomalous Ekman upwelling of warmer water in the salinity-stratified circumpolar region. This highlights an apparent divergence in literature about the sign of the SO SST anomalies associated with a SAM-like pattern. A similar lack of consensus also carries over to studies which explore the connection between the westerly winds and SO sea ice. Hall and Visbeck (2002) suggest that a positive SAM causes sea ice expansion, while Sigmond and Fyfe $(2010,2014)$ demonstrate that poleward intensification (forced by ozone depletion) is associated with a decrease in sea ice extent.

Ferreira et al. (2015) propose a theoretical framework that can resolve this ostensible disagreement about the sign of the SST anomaly associated with a poleward intensification of the westerlies. They use two different coupled GCMs to demonstrate that the SO response to winds in forced ozone depletion simulations is timescale-dependent. An atmospheric pattern similar to a positive SAM triggers short-term cooling followed by slow warming around Antarctica. The fast response is dominated by horizontal Ekman drift advecting colder water northward, while the slow response is sustained by Ekman upwelling of warmer water. Ferreira et al. (2015) show that the transition between the cooling and warming regime differs between two coupled GCMs and therefore can be highly model-dependent.

In our work we examine how the SO responds to a poleward intensification of the westerlies in 23 state-of-the-art CMIP5 coupled models (Taylor et al. 2012). By analyzing the GCMs' control simulations, we are able to study the relationship between SAM and SO SST anomalies $\left(55^{\circ} \mathrm{S}-70^{\circ} \mathrm{S}\right)$ even in models which have not performed wind override experiments or targeted ozone depletion simulations. In agreement with Ferreira et al. (2015), our findings suggest that anomalous Ekman transport may affect the SO response to SAM on interannual and decadal timescales. Furthermore, we interpret the diversity in the fast and slow responses across the CMIP5 ensemble in terms of the models' time-mean SO stratification. Finally, we use observational data for the ocean temperature climatology to constrain the SST step response function of the real SO.

\section{Data and methods}

The GCMs used in this study have made their experimental results publicly available through the CMIP5 initiative 
(Taylor et al. 2012). In our ensemble we include 23 models that have archived their output of ocean potential temperature, SST, and sea level pressure (SLP). We examine data from the CMIP5 preindustrial control simulations (piControl), which do not have any sources of external forcing. Thus all climate anomalies that we observe in these experiments can be attributed to internal variability. Moreover, the control simulations are hundreds of years long allowing us to perform statistical analysis with large samples of data. Table 1 provides additional information about the length of individual CMIP5 simulations. In order to conduct our analysis consistently across the ensemble, we convert all model output fields to the same regular latitude-longitude grid $\left(0.5^{\circ} \times 1^{\circ}\right)$. In the case of threedimensional fields, we also interpolate the original output onto the same depth-based vertical coordinate system with 40 levels.

We define an annual-mean index for the SAM in each model as the first principal component of variability in SLP south of $20^{\circ} \mathrm{S}$. Positive values of this index correspond to a poleward intensification of the westerly winds. In order to remove the secular drift, we linearly detrend the SAM timeseries.

Table 1 List of CMIP5 control Simulations

\begin{tabular}{lc}
\hline Model name & $\begin{array}{c}\text { Control run } \\
\text { length (years) }\end{array}$ \\
\hline ACCESS1-0 & 500 \\
ACCESS1-3 & 500 \\
BCC-CSM1.1 & 500 \\
CanESM2 & 996 \\
CCSM4 & 1051 \\
CESM1(CAM5) & 319 \\
CMCC-CM & 330 \\
CNRM-CM5 & 850 \\
GFDL CM3 & 500 \\
GFDL-ESM2G & 500 \\
GFDL-ESM2M & 500 \\
GISS-E2-H & 540 \\
GISS-E2-R & 550 \\
IPSL-CM5A-LR & 1000 \\
IPSL-CM5A-MR & 300 \\
IPSL-CM5B-LR & 300 \\
MIROC5 & 670 \\
MIROC-ESM & 630 \\
MPI-ESM-LR & 1000 \\
MPI-ESM-MR & 1000 \\
MRI-CGCM3 & 500 \\
NorESM1-M & 501 \\
NorESM1-ME & 252 \\
\hline
\end{tabular}

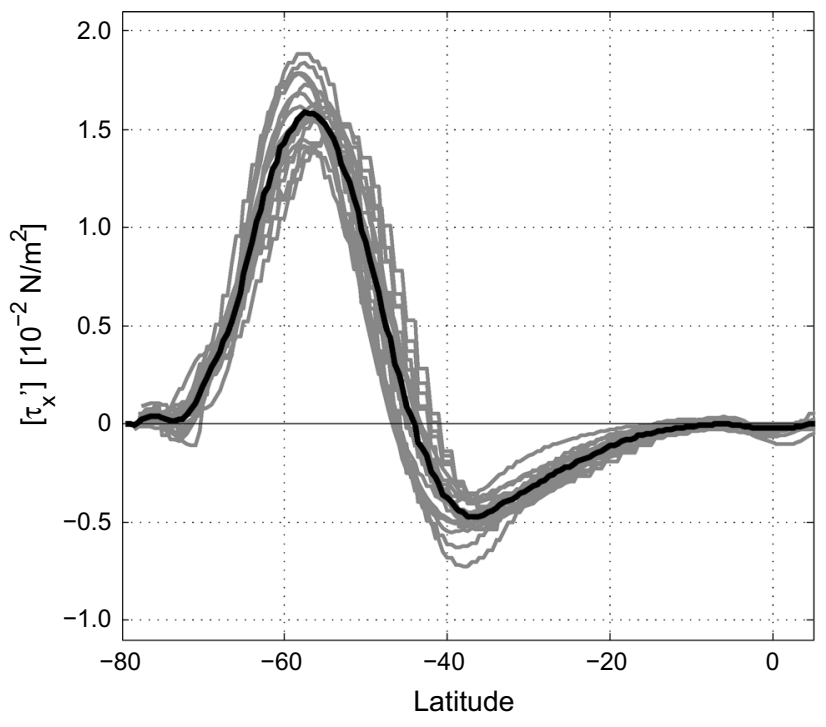

Fig. 2 The annual- and zonal-mean zonal wind stress anomaly at the ocean surface $\left[\tau_{x}^{\prime}\right]\left[10^{-2} \mathrm{~N} / \mathrm{m}^{2}\right]$ associated with a $1 \bar{\sigma}_{S A M}{ }^{E n s} \mathrm{SAM}$ event: individual model curves rescaled by ${\overline{\sigma_{S A M}}}^{\text {Ens }} / \sigma_{S A M}$ (gray) and the ensemble mean (black)

We furthermore consider the annual- and zonal-mean zonal wind stress $\left[\tau_{x}\right]\left[\mathrm{N} / \mathrm{m}^{2}\right]$ at the ocean surface for the CMIP5 models that have provided this field. Hereafter, we use [.] to denote the zonal averaging operator. At each latitude we regress $\left[\tau_{x}\right]$ against the model's SAM index and estimate the anomaly $\left[\tau_{x}^{\prime}\right]$ associated with a one standard deviation increase in the SAM, $1 \sigma_{S A M}$. However, in our intercomparison we have to take into account differences in the magnitude of SAM variability across the set of CMIP5 models. We thus calculate ${\overline{\sigma_{S A M}}}^{E n s}$, the ensemble mean of the index standard deviations $\sigma_{S A M}$. We then rescale each $\left[\tau_{x}^{\prime}\right]$ estimate by the nondimensional ratio ${\overline{\sigma_{S A M}}}^{\text {Ens }} / \sigma_{S A M}$ (Fig. 2). After rescaling, the different CMIP5 models exhibit very similar peak amplitudes and latitudinal structures of the wind stress anomaly associated with a $+1{\overline{\sigma_{S A M}}}^{\text {Ens }}$ SAM event.

We then calculate an area-weighted average of the annual-mean SST anomalies between $55^{\circ} \mathrm{S}$ and $70^{\circ} \mathrm{S}$ (hereafter referred to as SO SST). We have chosen this latitude range because the anomalous westerlies associated with SAM induce northward transport and upwelling in this zonal band. Further north, the wind anomaly gives rise to downwelling. As with the SAM index, we detrend the SST timeseries to eliminate the long-term drift. A comparison of the SO SST anomalies against the SAM index in CMIP5 models shows negative correlations at short lags (Fig. 3). This is reminiscent of the synchronous evolution of westerly winds and SO SST seen in observations (Fig. 1).

For each GCM, we estimate the impulse response function $G$ (a quasi-Green's function) of SO SST with respect 
Fig. 3 Timeseries from the control simulation of model CCSM4: the SAM index in gray and the Southern Ocean (SO)

SST anomaly averaged between $55^{\circ} \mathrm{S}$ and $70^{\circ} \mathrm{S}$ in black. Each index is detrended and rescaled by its standard deviation. The SST scale is shown on the left vertical axis, and the reversed scale for the SAM index is shown on the right. The SO SST is negatively correlated with the SAM index at a lag of 1 year $(R=-0.37)$

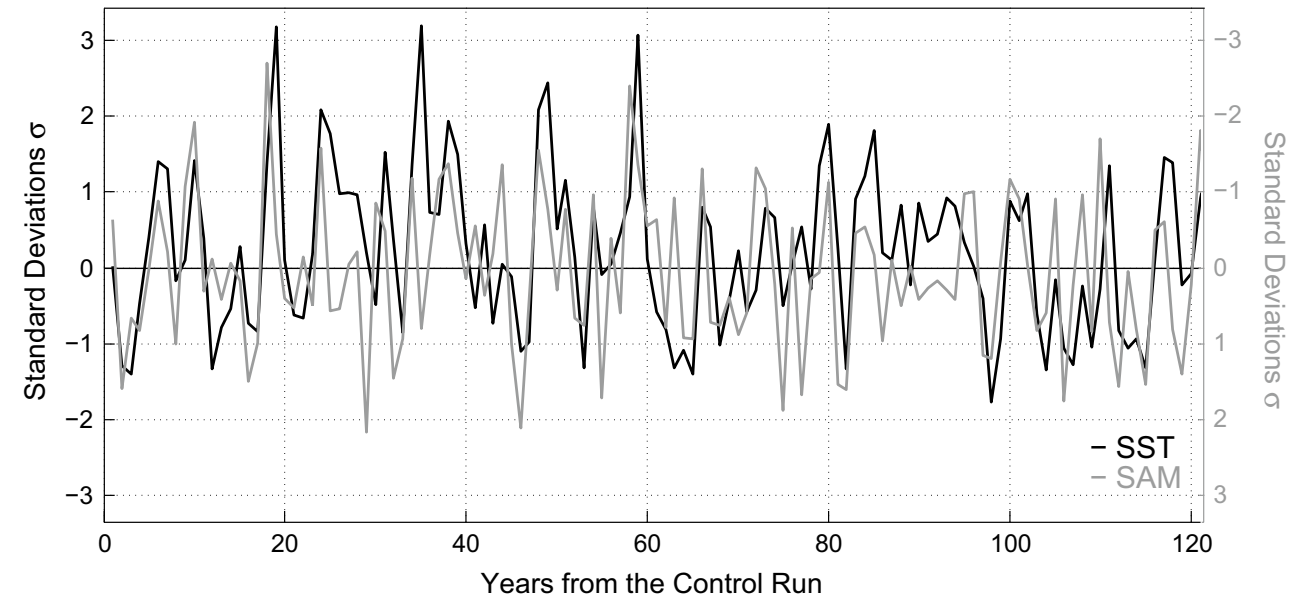

to the SAM index. Following Hasselmann et al. (1993), we represent the temperature timeseries as a convolution of $G$ with a previous history of the SAM forcing:

$$
\begin{aligned}
\operatorname{SST}(t) & =\int_{0}^{+\infty} G(\tau) \operatorname{SAM}(t-\tau) d \tau+\varepsilon \\
& \approx \int_{0}^{\tau_{\max }} G(\tau) \operatorname{SAM}(t-\tau) d \tau+\varepsilon,
\end{aligned}
$$

where $\operatorname{SAM}(t)$ is the SAM index normalized by its standard deviation $\sigma_{S A M}, \tau$ is the time lag in steps of years, $\tau_{\max }$ is an imposed maximum cutoff lag, and $\varepsilon$ is residual noise. The underlying assumption in Eq. (1) is that the ocean responds to SAM forcing as a linear system, and that the SO SST does not exert a large local feedback on the SAM on the relevant interannual and interdecadal timescales. In addition to the SAM, other modes of natural variability also influence the SO very strongly (e.g., see Langlais et al. 2015), and this impact is captured by the nonnegligible residual term $\varepsilon$. We discretize (1) to obtain

$\operatorname{SST}(t) \approx \sum_{i=0}^{I} G\left(\tau_{i}\right) \operatorname{SAM}\left(t-\tau_{i}\right) \Delta \tau+\varepsilon$, with $\tau_{I}=\tau_{\max }$,

where coefficients $G\left(\tau_{i}\right)$ represent the response at different time steps after an impulse perturbation of magnitude $\sigma_{S A M}$. Each time interval $\Delta \tau$ is equal to 1 year.

We then use a multiple linear least-squares regression of the SO SST signal against the lagged SAM index to estimate $G\left(\tau_{i}\right)$ for $i=0, \ldots, \tau_{\max }$. When performing the regression, we divide the annual SAM timeseries into overlapping segments, each of length $\tau_{\max }$. We then rescale the estimated impulse response functions for each GCM, where we multiply $G(\tau)$ by the corresponding nondimensional ratio ${\overline{\sigma_{S A M}}}^{E n s} / \sigma_{S A M}$.

By selecting multiple shorter SST and SAM timeseries from the full control simulation and by varying the cutoff lag $\tau_{\max }$, we obtain a spread of estimates for the impulse response function $G(\tau)$ in a given model. Table 2 lists our fitting parameters and their values. For each model, we have more than 350 individual fits corresponding to different parameter choices. We use the residuals $\varepsilon$ to quantify the uncertainty $\sigma_{\text {ImpulseFit }}(t)$ on each of these least squares regressions. Figure $4 \mathrm{a}$ shows examples of impulse response estimates for three CMIP5 models, rescaled by ${\overline{\sigma_{S A M}}}^{E n s} / \sigma_{S A M}$. Multiple fits span envelopes of uncertainty, while vertical bars denote the error margins $\sigma_{\text {ImpulseFit }}(t)$ on each fit. Note that in our analysis we use annual-mean SST. Hence the estimated Year 0 response is not zero, as it represents an average of the SST anomaly over the first months after a positive SAM impulse.

We integrate the impulse response function fits to obtain a spread of estimates for the SO step response function:

$S S T_{\text {Step }}(t)=\int_{0}^{t} G(\tau) d \tau \approx \sum_{i=0}^{t} G(\tau) \Delta \tau$,

where $t \leq \tau_{\max }$ and $\Delta \tau=1$ year.

Each of the estimates corresponds to a different combination of start and end times for the timeseries, as well as different choices of $\tau_{\max }$. We calculate the mean $\operatorname{SST}_{\text {Step }}(t)$ and the standard deviation $\sigma_{\text {Spread }}(t)$ which characterize our envelope of step response functions for a given model. We furthermore use the $\sigma_{\text {ImpulseFit }}(t)$ values to constrain the margin of error $\sigma_{\text {StepFit }}(t)$ on each individual estimate in our spread. We then combine $\sigma_{\text {StepFit }}(t)$ and $\sigma_{\text {Spread }}(t)$ in quadrature in order to quantify the total uncertainty $\sigma_{S S T s t e p}(t)$ on the mean $S S T_{\text {Step }}(t)$ for a given GCM. Figure $4 \mathrm{~b}$ shows example step response functions calculated for the three models presented in Fig. 4a.

The step response results are integral quantities, and hence they are smoother than the corresponding impulse response functions. However, a drawback is that the 
Fig. 4 Annual-mean response of the Southern Ocean SST anomaly $\left[{ }^{\circ} \mathrm{C}\right]$ to: a a positive impulse perturbation in the SAM index of magnitude equal to ${\overline{\sigma_{S A M}}}^{\text {Ens; }}$; b a positive step increase in the SAM index of magnitude equal to ${\overline{\sigma_{S A M}}}^{\text {Ens }}$. Different colors are used to distinguish the response functions in the three CMIP5 models shown: CCSM4, MPIESM-MR, and CNRM-CM5. For each model, we have shown only 100 different fits to illustrate the envelopes of uncertainty, and we have not spanned the full parameter space laid out in Table 2. Vertical error bars denote the margin of error for each fit
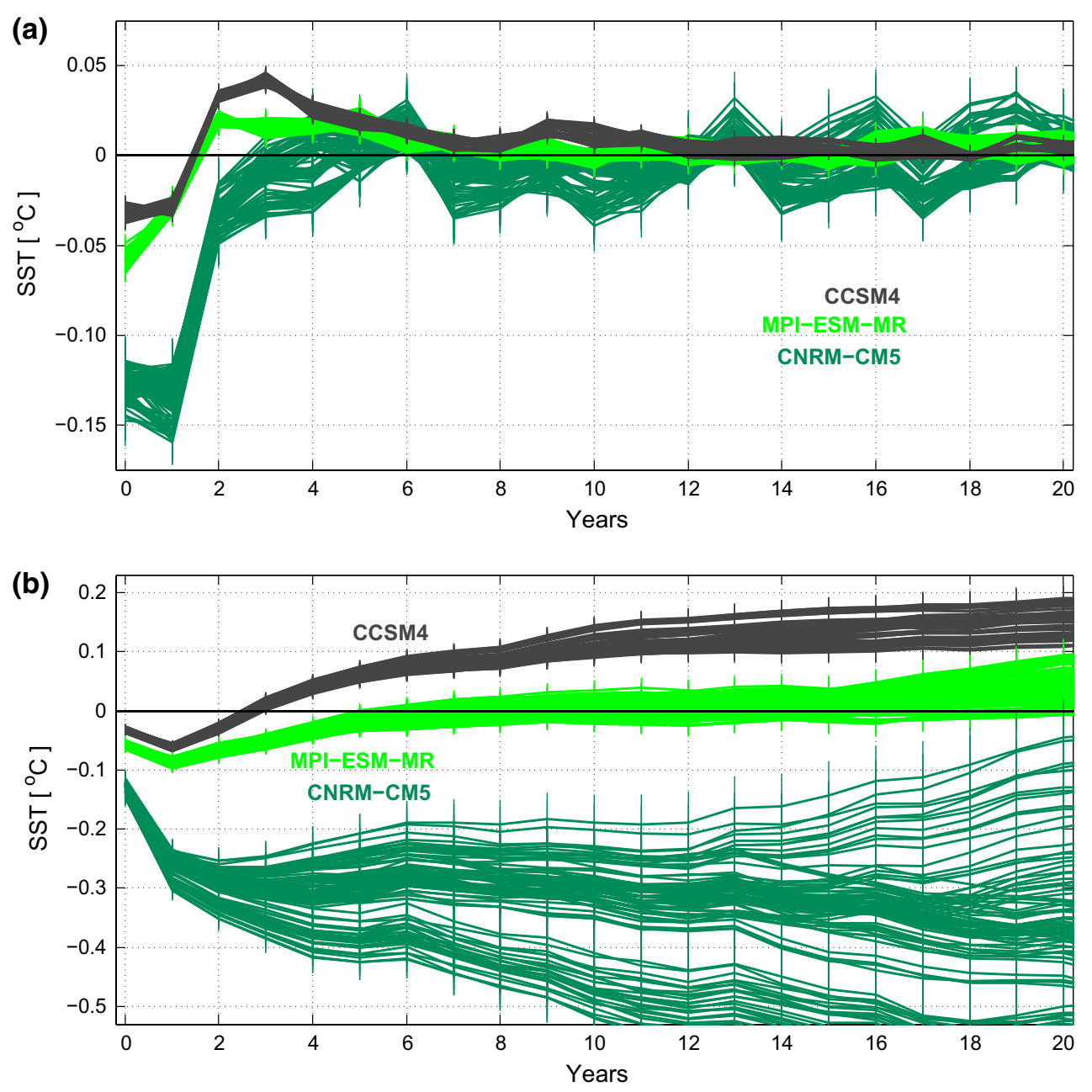

Table 2 Fitting parameters

\begin{tabular}{lc}
\hline Fitting parameter & Parameter space \\
\hline$\tau_{\max }$ (years) & $50,75,100,150$ \\
Offset from the beginning of the full & $0,2.5,5,7.5,10,15$, \\
timeseries [\% of simulation length] & $20,25,30,35,40$ \\
Offset from the end of the full timeseries & $0,2.5,5,7.5,10,15$, \\
[\% of simulation length] & $20,25,30$ \\
\hline
\end{tabular}

We vary the maximum cutoff lag $\tau_{\max }$ (years). Note that we use only $\tau_{\max }=50$ years and $\tau_{\max }=75$ years for models whose control simulation is shorter than 350 years. We use four different values of $\tau_{\max }$ where longer simulations are available. We also select shorter SST timeseries from the full control simulations by removing a certain percent of time steps from the beginning and the end of each model run

integrated errors grow larger in time. Nevertheless, Fig. 4b demonstrates that even with generous envelopes of uncertainty and large error bars on the individual fits, we can still distinguish the estimated step response functions of different CMIP5 models.
We use synthetic noisy signals and artificially constructed systems with known step responses in order to test our methodology. The verification procedure is described and illustrated in detail in "Appendix" section. Multiple tests confirm the validity of our approach for estimating the SO response functions.

\section{Results}

Our estimated step response functions suggest notable intermodel differences in the SO SST response to SAM across the CMIP5 ensemble (Fig. 5). Although all GCMs show initial cooling, many of them transition into a regime of gradual warming. If forced with a positive step increase in the SAM, a number of CMIP5 modelssuch as CanESM2, CCSM4, and CESM1(CAM5)-are expected to show positive SST anomalies in the SO within a few years. In contrast, other ensemble members, including CNRM-CM5 and GFDL-ESM2M, do not exhibit such nonmonotonic response to a poleward intensification of 
Response to a $1 \sigma$ Step Increase in the SAM Index

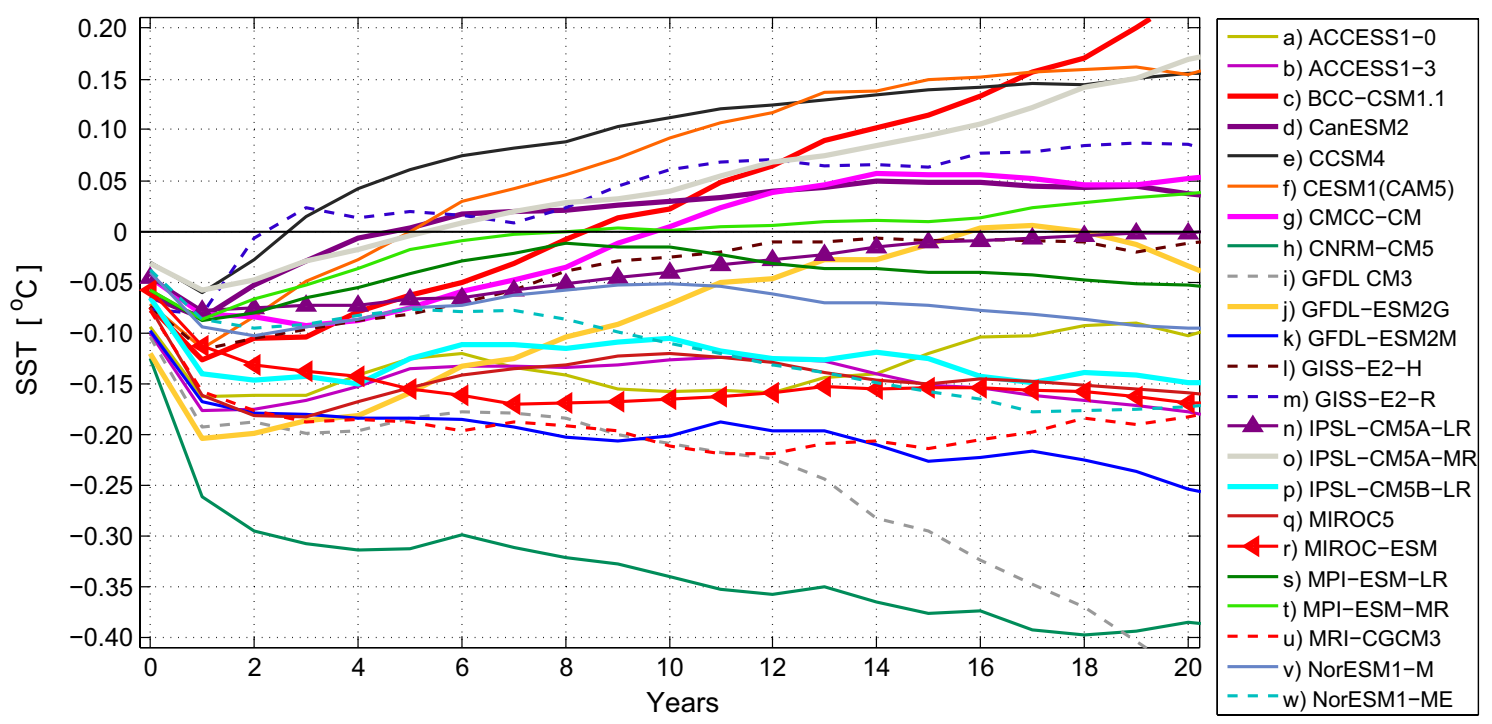

Fig. 5 Annual-mean responses of the Southern Ocean SST $\left[{ }^{\circ} \mathrm{C}\right]$ to a step increase in the SAM index of magnitude $\overline{\sigma S A M}^{\text {Ens — }}$ comparison across the CMIP5 ensemble. For each model we have shown only the mean estimate $S S T_{S t e p}(t)$

the westerlies and instead maintain negative temperature anomalies persisting for longer than a decade. What sets this intermodel diversity in the way the SO reacts to SAM on short and long timescales?

Following Ferreira et al. (2015), we examine whether the fast cooling regime is related to northward wind-driven transport, advecting colder water up the climatological SO SST gradient. We expect that on short timescales the SAMinduced anomalous SST tendency $d S S T^{\prime} / d t$ in $\left[{ }^{\circ} \mathrm{C} /\right.$ year] is dominated by horizontal advection and scales as

$\frac{d S S T^{\prime}}{d t} \approx \frac{\left[\tau_{x}^{\prime}\right]}{\rho_{0} f Z_{E k}} \partial_{y} \overline{[S S T]}+F$,

where $\left[\tau_{x}^{\prime}\right]$ is the zonally averaged zonal component of the anomalous surface wind-stress associated with SAM, $\rho_{0}$ is a reference density, $f$ is the Coriolis parameter, $Z_{E k}$ is the thickness of the Ekman layer, $\partial_{y} \overline{[S S T]}$ is the meridional gradient of the zonally averaged climatological SST, and $F$ denotes an anomalous air-sea heat flux forcing on the SST. As in Ferreira et al. (2015), we have assumed that eddy compensation in the thin Ekman layer is much smaller than the anomalous northward wind-driven transport. Since we have rescaled each SST response function by the nondimensional ratio ${\overline{\sigma_{S A M}}}^{E n s} / \sigma_{S A M}$, we can assume that the hypothetical SAM step-increase is the same for all models in our ensemble. Thus we have eliminated some of the intermodel spread due to different $\left[\tau_{x}^{\prime}\right]$ across the ensemble.

For a $1 \sigma$ SAM event in these CMIP5 models, the typical zonal wind-stress anomaly $\left[\tau_{x}^{\prime}\right]$ around $60^{\circ} \mathrm{S}$ is approximately $1.4 \times 10^{-2} \mathrm{~N} / \mathrm{m}^{2}$ (Fig. 2), and a typical meridional SST gradient $\partial_{y} \overline{[S S T]}$ is approximately $0.35{ }^{\circ} \mathrm{C} / 100 \mathrm{~km}$ with a range between 0.26 and $0.43{ }^{\circ} \mathrm{C} / 100 \mathrm{~km}$ across the ensemble. If we neglect $F$ in (4), and assume a $Z_{E k}=30$ $\mathrm{m}$ deep Ekman layer, a reference density of $\rho_{0}=1027.5$ $\mathrm{m} / \mathrm{kg}^{3}$, and a Coriolis parameter $f$ corresponding to $60^{\circ} \mathrm{S}$, we estimate a scaling for the Year 1 response of approximately $-0.3 \pm 0.06^{\circ} \mathrm{C}$. This is very similar to the typical fast response of $S S T^{\prime} \approx-0.15^{\circ} \mathrm{C}$ for our CMIP5 ensemble (Fig. 6a).

We then perform a weighted least squares linear regression of the estimated Year 1 cooling anomalies from our step responses against $\partial_{y} \overline{[S S T]}$ averaged between $55^{\circ}$ and $70^{\circ} \mathrm{S}$, where we weight each datapoint by $1 / \sigma_{\text {SSTstep }}^{2}$. We see a strong anticorrelation with a Pearson's $R=-0.72$ (Fig. 6a). This result is significant at the $5 \%$ level with $p<0.01$ and highlights the importance of horizontal Ekman transport for the fast cooling regime during a positive phase of the SAM.

We also consider the role of Ekman upwelling for influencing the slow response to a step increase in the SAM index. Following Ferreira et al. (2015), we take an Ansatz that on longer timescales the anomalous SST tendency $d S S T^{\prime} / d t$ in $\left[{ }^{\circ} \mathrm{C} /\right.$ year] scales as

$\frac{d S S T^{\prime}}{d t} \approx \gamma T_{s u b}^{\prime}-\lambda S S T^{\prime}$,

where $T_{s u b}^{\prime}$ is a subsurface temperature anomaly entrained into the mixed layer on a timescale $\gamma^{-1}$, and $\lambda$ is a coefficient of air-sea damping. In turn, as in Ferreira et al. (2015), we assume that the subsurface anomaly $T_{s u b}^{\prime}$ is dominated by the anomalous upwelling along the SO vertical temperature inversion, 

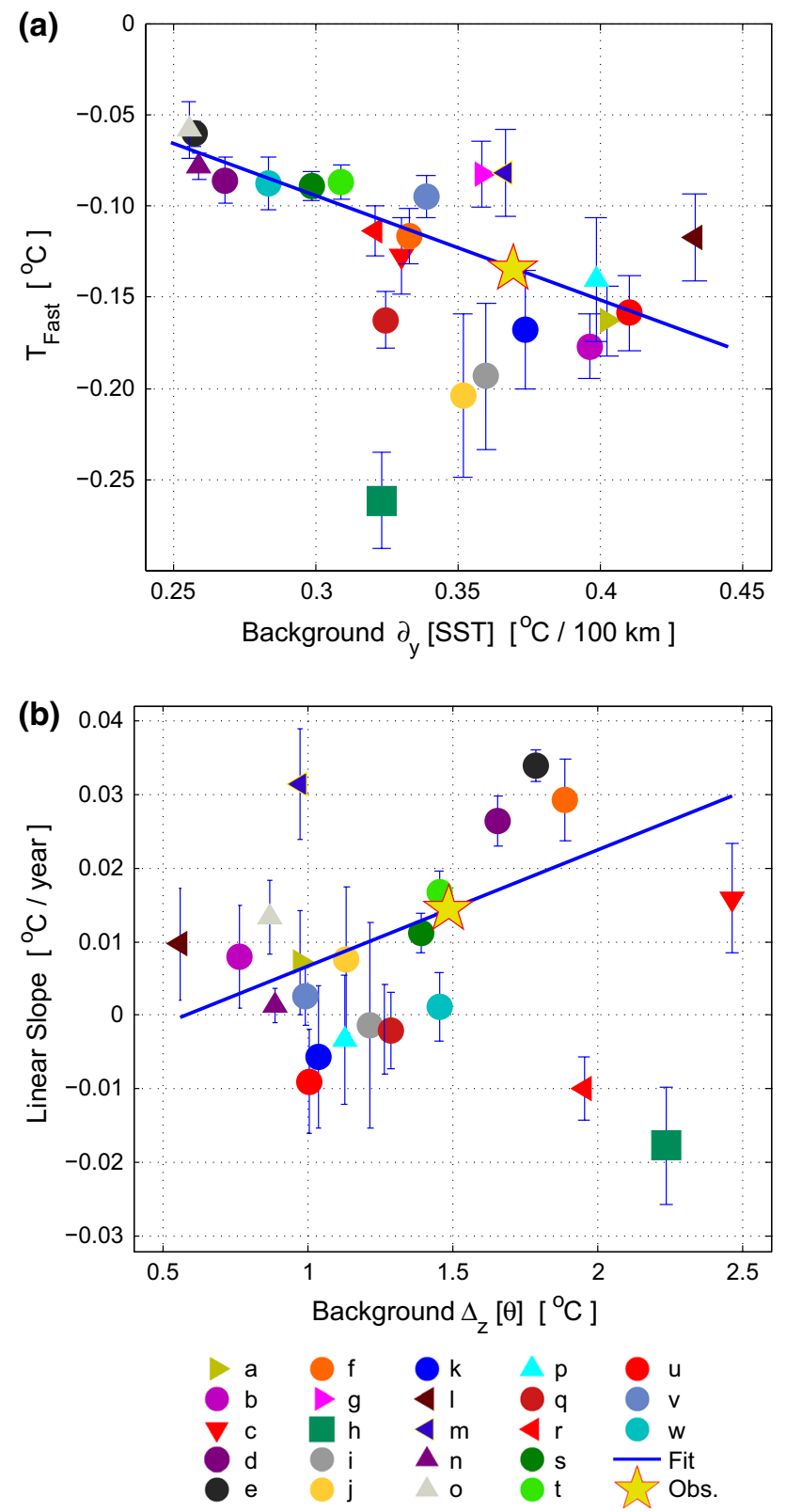

Fig. 6 a Relationship between the models' climatological meridional SST gradients $\left.\partial_{y} \overline{[S S T}\right]\left[{ }^{\circ} \mathrm{C} / 100 \mathrm{~km}\right]$ in the Southern Ocean $\left(55^{\circ}-70^{\circ} \mathrm{S}\right)$ and the Year $1 \mathrm{SST}$ response $S S T_{\text {Step }}(t=1)\left[{ }^{\circ} \mathrm{C}\right]$ to a step perturbation in the SAM index. The vertical error bars correspond to $\sigma_{S S T s t e p}(t=1)$. b Relationship between the climatological temperature inversion $\Delta_{z} \overline{[\theta]}\left[{ }^{\circ} \mathrm{C}\right]$ in the Southern Ocean (depth levels $67-510 \mathrm{~m}$ ) and the SST warming rate $\Lambda\left[{ }^{\circ} \mathrm{C} /\right.$ year $]$ which characterizes the slow response to a step increase in the SAM index. Legend: both $\mathbf{a}$ and $\mathbf{b}$ use the same color code and alphabetical order as in Fig. 5 to distinguish the CMIP5 models analyzed. Straight lines indicate linear fits to the scatter where each data point in the regression analysis is weighted by the inverse of the SE squared. The yellow stars denote estimates for the response of the real Southern Ocean based on observed climatological meridional SST gradients between $55^{\circ} \mathrm{S}$ and $70^{\circ} \mathrm{S}$ [NOAA Reynolds Optimum Interpolation, Reynolds et al. (2002)] and the climatological $\Delta_{z} \overline{[\theta]}$ inversion [Hadley Centre EN4 dataset, Good et al. (2013)] $\frac{d T_{s u b}^{\prime}}{d t} \approx-\frac{\delta}{\rho_{0}}\left(\frac{\partial}{\partial y}\left[\frac{\tau_{x}^{\prime}}{f}\right]\right) \frac{\Delta_{z} \overline{[\theta]}}{Z_{s u b}}$

where $\Delta_{z} \overline{[\theta]}$ in ${ }^{\circ} \mathrm{C}$ is the inversion (i.e., the maximum vertical contrast) in the time-mean ocean potential temperature within a layer of thickness $Z_{s u b}$. Parameter $\delta$ is a nondimensional factor $0 \leq \delta \leq 1$ that indicates whether we have full ( $\delta=0)$, partial $(0<\delta<1)$, or no $(\delta=1)$ compensation of the anomalous Ekman upwelling by the eddy-induced circulation.

On timescales $t_{\text {lin }} \ll \lambda^{-1}$, we can assume that the slow SO SST response rate evolves approximately linearly,

$$
\begin{aligned}
\left.\frac{d S S T^{\prime}}{d t}\right|_{t=t_{\text {lin }}} & \approx-t_{\text {lin }} \gamma \frac{d T_{\text {sub }}^{\prime}}{d t} \\
& \approx-t_{\text {lin }} \gamma \frac{\delta}{\rho_{0}}\left(\frac{\partial}{\partial y}\left[\frac{\tau_{x}^{\prime}}{f}\right]\right) \frac{\Delta_{z} \overline{[\theta]}}{Z_{s u b}}
\end{aligned}
$$

In the CMIP5 models, a $1 \sigma$ SAM event is typically associated with an anomalous meridional gradient in the zonal wind stress curl at $60^{\circ} \mathrm{S}$ of approximately $\left[\tau_{x}^{\prime}\right] \approx 7.0 \times 10^{-4}$ $\mathrm{N} / \mathrm{m}^{2}$ per degree latitude (Fig. 2). The typical SO potential temperature inversion in the zonal average is $\Delta_{z} \overline{[\theta]} \approx 1.5^{\circ} \mathrm{C}$ over a depth range of $Z_{s u b} \approx 450 \mathrm{~m}$, with variations between 0.6 and $2.5{ }^{\circ} \mathrm{C}$ across the ensemble. We assume an eddy compensation with $\delta=30 \%$. We then use $f$ and $\beta=d f / d y$ characteristic of $60^{\circ} \mathrm{S}$, as well as $\rho_{0}=1027.5 \mathrm{~kg} / \mathrm{m}^{3}$, to obtain a scaling for the subsurface warming rate $\frac{d T_{s u b}^{\prime}}{d t} \approx 0.16{ }^{\circ} \mathrm{C} /$ year. Assuming a mixed layer entrainment timescale of $\gamma^{-1} \approx 1.5$ years, we estimate that in the Year 3 after a $1 \sigma$ step-increase in the SAM, the SST warming rate is approximately $d S S T^{\prime} / d t \approx 0.04{ }^{\circ} \mathrm{C} /$ year with a range of $0.02-0.06{ }^{\circ} \mathrm{C} /$ year. This value is on the same order of magnitude as the estimated slow responses between Year 1 and Year 7 in the CMIP5 ensemble (Fig. 6b)

If the slow response on these timescales is indeed governed by upwelling of warmer water below the mixed layer, the bolus circulation cannot be neglected (Ferreira et al. 2015). As discussed by Ferreira et al. (2015), local eddy compensation at depths of hundreds of meters may be much larger than in the thin Ekman layer. Moreover, the fraction of eddy compensation $(1-\delta)$ is model dependent. The representation of mixed layer entrainment processes also differs across the CMIP5 ensemble. We therefore expect that both $\delta$ and $\gamma$ may contribute to the intermodel spread in the slow SST response, along with the climatological SO temperature inversion $\Delta_{z} \overline{[\theta]}$.

Using Eq. (7) as an Ansatz, we test the importance of the background thermal stratification $\Delta_{z} \overline{[\theta]}$ for contributing to differences in the slow response among CMIP5 GCMs. We calculate the average slope $\Lambda$ [ ${ }^{\circ} \mathrm{C} /$ year] of the step response functions between Year 1 and Year 7 after a step increase in 
the SAM and the standard error (SE) for each model estimate. In many models this slope is predicted to be positive, corresponding to a slow warming. We compare $\Lambda$ against the vertical temperature inversion $\Delta_{z} \overline{[\theta]}$ for the area-averaged water column between $55^{\circ} \mathrm{S}$ and $70^{\circ} \mathrm{S}$ and between depths of 67 and $510 \mathrm{~m}$. Above $67 \mathrm{~m}$ the models in our ensemble exhibit no SO temperature inversion. We have chosen a vertical range extending down to $510 \mathrm{~m}$ because this encompasses the winter maximum mixed layer depths in the SO climatology of CMIP5 models (Salleé et al. 2013). We perform a least squares regression of $\Lambda$ against $\Delta_{z} \overline{[\theta]}$, where each data point is weighted by the inverse of the SE squared. We find that the slow response rates $\Lambda$ across models are positively correlated with $\Delta_{z} \overline{[\theta]}$, with $R=+0.45$ (Fig. 6b). This result is statistically significant with $p<0.05$. It emphasizes that Ekman upwelling acting on the background temperature gradients contributes substantially to the intermodel spread in the slow SST responses to SAM.

The correlation between the rate $\Lambda$ and the vertical temperature inversion $\Delta_{z} \overline{[\theta]}$ is not as strong as our result linking the rapid cooling response to the meridional SST gradients. We propose that the slow regime is more complicated than the fast one due in part to air-sea heat exchange (Ferreira et al. 2015) but also due to multiple diverse processes within the ocean domain such as eddy compensation and mixed layer entrainment represented by coefficients $\delta$ and $\gamma$ in Eq. (7).

We acknowledge that the data points in our intermodel correlation analysis of the fast and slow response (Fig. 6a, b) do not necessarily represent independent samples. Some CMIP5 ensemble members are in fact multiple versions of the same GCM with a different horizontal resolution (e.g., MPI-ESM-LR and MPI-ESM-MR). Other ensemble members have been developed by the same institution (e.g., GFDL-CM3, GFDL-ESM2G, and GFDL-ESM2M) or belong to the same family of models and hence share common code or parameterizations (Knutti et al. 2013). Thus it is possible that we are inflating our sample size by redundantly including interdependent GCMs. On the other hand, we cannot know a priori which models may exhibit similarities or differences solely on the basis of their common genealogy. For instance, models MIROC-ESM and MIROC5 are related, but their predicted fast SST responses to SAM are statistically different (Fig. 6a).

Nevertheless, comparing groups of models with different fast and slow responses to SAM provides further evidence to support the results of our correlation analysis. We consider the 10 models in our ensemble that are expected to show the strongest (weakest) cooling in their Year 1 response and composite their annual-mean SST climatology (Fig. 7a, b). Consistent with Fig. 6a, we see that a colder fast response is associated with larger meridional gradients in the background SST. Moreover, models which
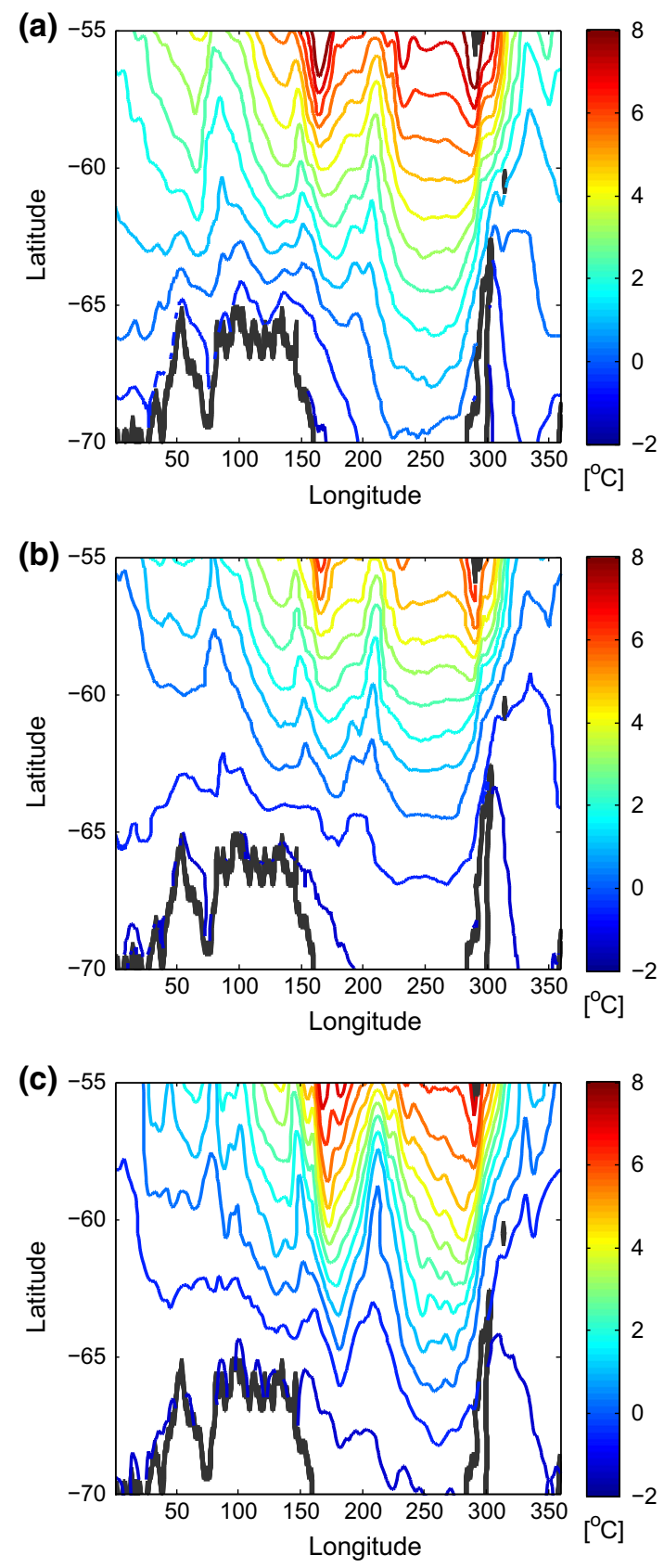

Fig. 7 Climatological annual-mean SST, with contours spaced $0.75{ }^{\circ} \mathrm{C}$ apart, from: a a composite of the 10 models expected to show the strongest cooling in Year 1; b a composite of the 10 models expected to show the weakest cooling in Year 1; $\mathbf{c}$ observations (Reynolds et al. 2002). The dark gray contour delimits continents and islands

exhibit a weak fast response have SO SST gradients that are too small compared to the observationally-based 19822014 SST climatology (Fig. 7c) from the Reynolds Optimum Interpolation Dataset (Reynolds et al. 2002).

Analogously, we composite the zonally-averaged annual-mean potential temperature climatology of the 10 
Fig. 8 Zonal- and annual-mean potential temperature climatology (the contour interval is $0.25^{\circ} \mathrm{C}$ apart). a A composite of the 10 models expected to show the smallest rate of SST increase in their slow response (dashed blue) contrasted against a composite of the 10 models expected to show the largest slow response (red); b, c same as in a but with gray contours denoting observations (Good et al. 2013)
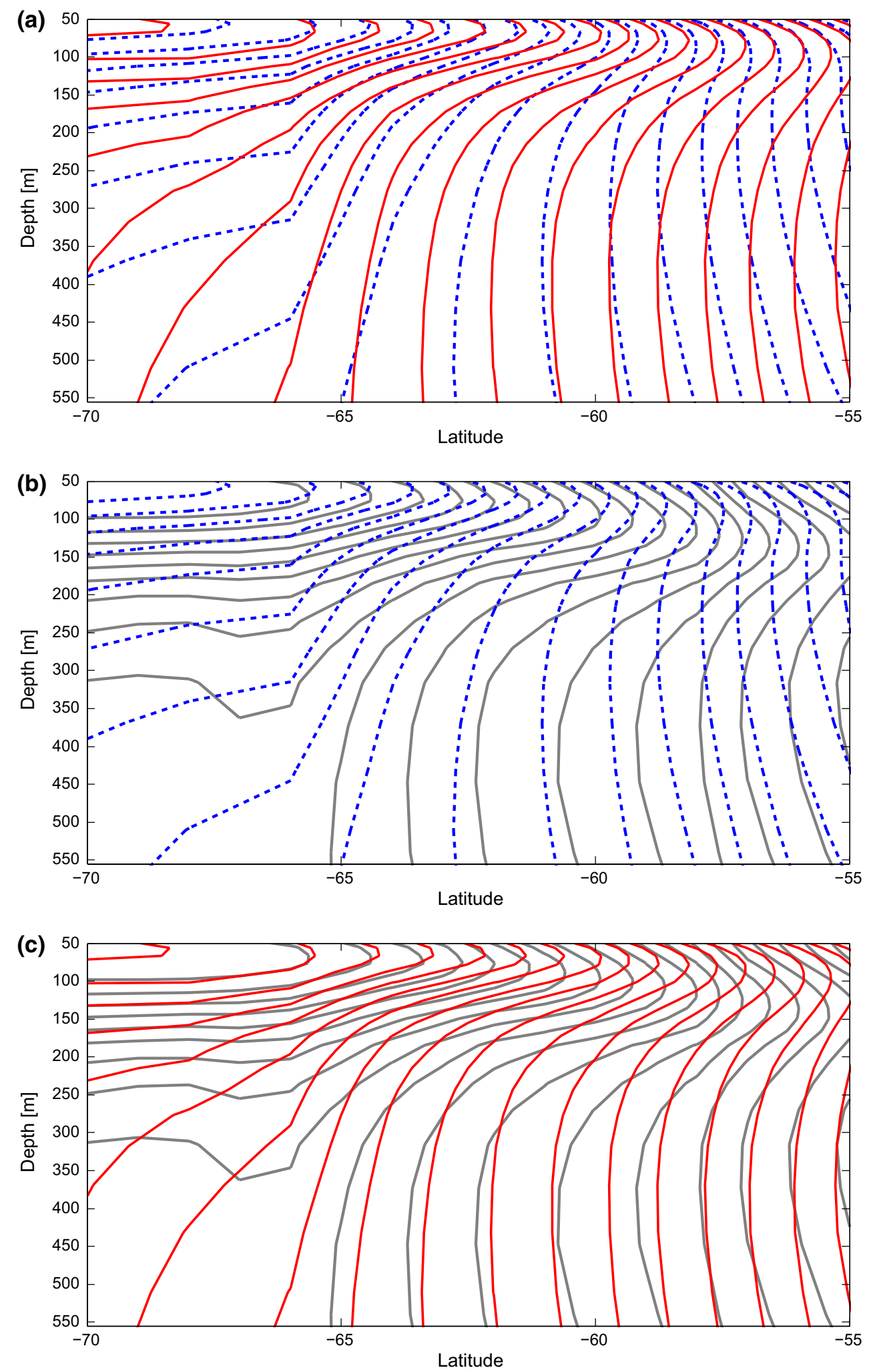

models with the greatest (smallest) estimated slow response rates (Fig. 8). A greater warming rate on slow timescales is associated with a larger vertical temperature inversion in the SO climatology. Models which show little or no slow surface warming response generally underestimate the temperature inversion seen in the Hadley EN4 1979-2013 observations (Good et al. 2013). In addition, the CMIP5 models as a whole show an inversion that is too close to 
the surface compared to the real SO. This bias in the inversion depth may be causing models to overestimate the rate at which the SAM-induced subsurface warming signal is communicated to the mixed layer.

Our composite analysis provides a simple but useful framework for comparing groups of CMIP5 models and contrasting them against observations of the SO. The results illustrate the relationship between the background temperature gradients and the SO response to SAM in agreement with our correlation analysis.

\section{Connecting our model-based results to the real Southern Ocean}

While acknowledging the limitations of our regression analysis (Fig. 6), we attempt to extend our CMIP5 results to the real SO and place an observational constraint on the SST response to SAM. We calculate the climatological meridional SST gradients $\partial_{y} \overline{[S S T]}$ using data from the Reynolds Optimum Interpolation (Reynolds et al. 2002) and compute a metric for time-mean vertical contrast in potential temperature $\Delta_{z} \overline{[\theta]}$ using the Hadley Centre EN4 product (Good et al. 2013). We use these observationally based climatological SO temperature gradients and the linear relationships found among CMIP5 models (Fig. 6) to estimate the fast and slow responses in the real SO (denoted with stars in Fig. 6a, b). Our results suggest an expected cooling of $-0.13{ }^{\circ} \mathrm{C}$ with an $\mathrm{SE}$ of $0.01{ }^{\circ} \mathrm{C}, 1$ year after a step increase in the SAM index. This is likely to be followed by a gradual SST warming at a rate of $0.014{ }^{\circ} \mathrm{C} /$ year with an SE of $0.003{ }^{\circ} \mathrm{C} /$ year.

We then calculate a range of model-based estimates for the real SO response following the bias-correction methodology of DeAngelis et al. (2015) as follows. We first quantify the bias that each model exhibits with respect to the observed $\partial_{y} \overline{[S S T]}$ and $\Delta_{z} \overline{[\theta]}$ in the SO. Then we use the linear relationships from Fig. 6 to quantify how a deviation from the observed $\partial_{y} \overline{[S S T]}$ or $\Delta_{z} \overline{[\theta]}$ introduces an expected bias in the models' fast and slow responses, respectively. Finally, these biases for the estimated fast and slow timescales are subtracted from the corresponding ensemble member's response (Fig. 9a, b). We assume that the uncertainty in our initial model-specific estimates is not affected by this linear bias-correction. We calculate weighted means and weighted standard deviations (SD) of the bias-corrected model spreads in the fast and slow responses, where we rescale each data point in our sample by the inverse of the SE squared. Note that the weighted bias-corrected ensemble means reproduce the same estimates for the real SO response as the linear relationships in Fig. 6: a fast cooling of $-0.13{ }^{\circ} \mathrm{C}$ followed by slow warming at a rate of $0.014{ }^{\circ} \mathrm{C} /$ year. Finally, we use our results to constrain an envelope of uncertainty on the step response of the real SO to SAM (see schematic Fig. 9c). Our bias-corrected analysis for the real SO suggest that the expected Year 1 cooling of $-0.13{ }^{\circ} \mathrm{C}$ has an ensemble SD of $\pm 0.027^{\circ} \mathrm{C}$, while the estimated slow response rate of $0.014{ }^{\circ} \mathrm{C} /$ year has an SD of $\pm 0.013{ }^{\circ} \mathrm{C} /$ year. Thus we infer from the observed climatology that the step response function of the real SO crosses over from negative to positive SST anomalies on a timescale of at least 5 years, possibly several decades, after a hypothetical step-increase in the SAM. Using a more direct approach based on an observationally-constrained model of the upper SO, (Hausmann et al. 2016) evaluate the response of SO SST to SAM and also predict a long crossover timescale in agreement with our result.

\section{Discussion and interpretation of the results}

In this study we have analyzed CMIP5 preindustrial control simulations and examined how SAM forces SO SSTs. In many GCMs the SST exhibits a two-timescale response to SAM: initial cooling followed by slow warming. As in Ferreira et al. (2015), we interpret the evolution of these temperature anomalies in terms of the wind-driven circulation redistributing the background heat reservoir. We show evidence that anomalous equatorward transport of colder water contributes to the fast cooling response south of $50^{\circ} \mathrm{S}$. Our results also suggest that the slow warming regime found in many GCMs is affected by Ekman upwelling of warmer water in the haline stratified SO.

Across the CMIP5 ensemble, we find a notable intermodel spread in the SO SST response to poleward intensification of the westerlies. We relate part of the diversity in the step response functions to differences in the background thermal stratification among the models. GCMs that have small meridional and large vertical temperature gradients in their SO climatology tend to cross over faster from an initial negative to a long-term positive SST response. Our results suggest that a realistic ocean climatology is one of the important prerequisites for successfully simulating the SST response to SAM.

The model-specific results of our analysis have implications for attribution studies which evaluate the effects of greenhouse gas forcing and ozone depletion on the SO. For example, Sigmond and Fyfe (2014) analyze CMIP3 and CMIP5 output to determine the impact of the ozone hole on SO sea ice. Similarly, Solomon et al. (2015) design and conduct numerical experiments with CESM1(WACCM) to study how ozone depletion affects the circulation and sea water properties of the SO. Such in-depth attribution studies often employ a limited set of GCMs-for instance, only a few CMIP5 modeling groups provide output from ozoneonly simulations (Sigmond and Fyfe 2014). However, 
Fig. 9 a Scatter: estimated fast responses $\left[{ }^{\circ} \mathrm{C}\right]$ after correcting for the model bias in the climatological meridional SST gradients relative to observations (same color code as in Fig. 6). Vertical error bars denote 2 SE. The horizontal black line is the weighted mean of the model estimates. The solid (dashed) gray lines denote one (two) weighted standard deviations (SD) of the spread. $\mathbf{b}$ Same as in (a) but for the slow response rates $\left[{ }^{\circ} \mathrm{C} /\right.$ year] after correcting for the bias in $\Delta_{z} \overline{[\theta]}$. c. Solid black lines: a schematic for the estimated response of the real SO SST $\left[{ }^{\circ} \mathrm{C}\right]$ based on (a) and (b). We show the ensemble mean bias-corrected fast response $\pm 1 \mathrm{SD}$. This is extended until Year 7 with lines matching the ensemble mean bias-corrected slow response \pm 1 SD. Dashed lines show a linear extrapolation at a constant rate or a constant temperature. Gray lines replicate the Fig. 5 SO SST step responses $\left[{ }^{\circ} \mathrm{C}\right]$
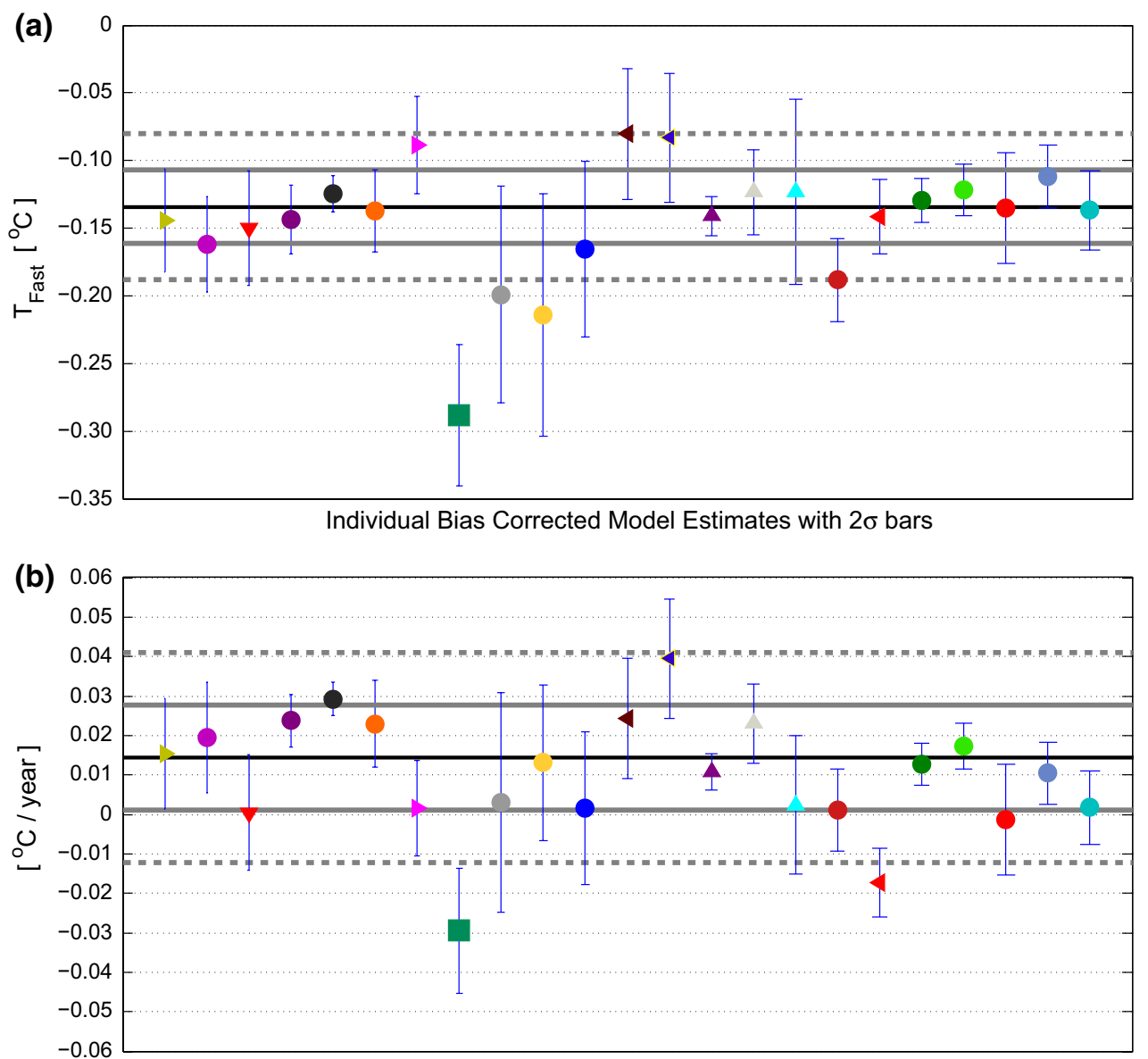

Individual Bias Corrected Model Estimates with $2 \sigma$ bars

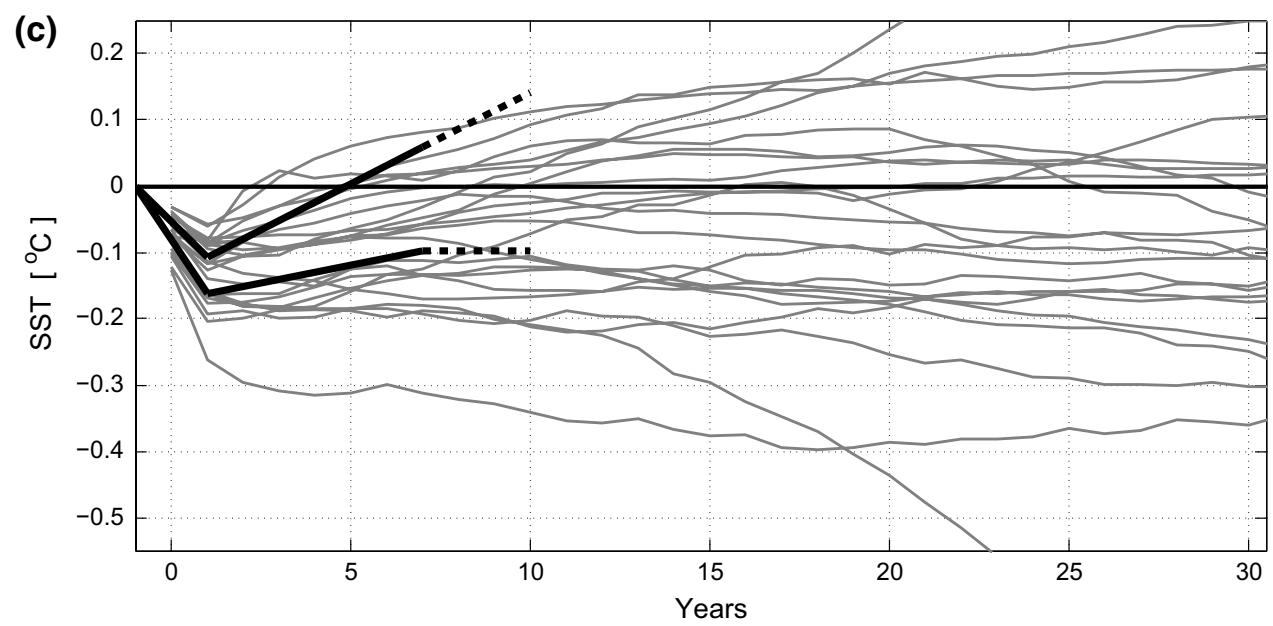

individual GCMs have various biases in their mean ocean climatology (e.g., Meijers 2014; Salleé et al. 2013). Thus, we emphasize that the outcome of attribution experiments can be sensitive to the choice of models used. Realistic background temperature gradients are a prerequisite for simulating successfully the response of the SO to a poleward intensification of the westerlies, as the one seen in numerical experiments with ozone depletion.
Our results also identify criteria for constraining and critically assessing future projections of the Southern Hemisphere SST anomalies. Under scenarios with extended greenhouse gas emissions and gradual ozone recovery, CMIP5 models predict a significant and lasting poleward intensification of the westerlies throughout the twenty-first century (Wang et al. 2014). Based on our analysis, we suggest that those models which have smaller biases in their 
climatological stratification provide better estimates of future SST anomalies in the SO.

We point out that in our analysis we have neglected seasonal variations in ocean stratification and their impact on the SO SST response to wind changes. Purich et al. (2016) emphasize that in the summer a warm surface lens caps the colder subsurface winter water. Therefore, during this season, anomalous Ekman upwelling may complement rather than counteract the cooling effect of northward Ekman transport.

Our study has further limitations in its ability to account for the multiple diverse processes that take place in the SO. For example, de Lavergne et al. (2014) show that there are large differences among the CMIP5 models in their representation of deep convection around Antarctica. It is possible that certain GCMs which do not have strong SO convection, such as BCC-CSM1.1 and CNRM-CM5 (de Lavergne et al. 2014), may not be able to efficiently communicate a subsurface temperature signal into the mixed layer. This in turn may affect the slow warming response to SAM in these models. The recurrence of convective and nonconvective periods in GCMs can also modify the variability of SO stratification about its mean climatology and affect the transition between the fast and slow SST responses (Seviour et al. 2016, in prep.).

Another potential deficiency in our work pertains to our treatment of atmosphere-ocean coupling. We have not explored any possible intermodel differences in the response of SO surface heat fluxes represented by terms $F$ and $-\lambda S S T^{\prime}$ in Eqs. (4) and (5). A recent estimate of the air-sea feedback strength in the SO by Hausmann et al. (2016) can provide guidance in the further assessment of modeled air-sea feedbacks and the possible impact of inter-model differences on the response to SAM.

In our linear response function analysis, we have also neglected other potential implications of atmosphere-ocean coupling. We have assumed that the SAM wind pattern forces the SST but not vice versa. However, Sen Gupta and England (2007) suggest that SO SST anomalies may feed back on the atmospheric circulation and increase the persistence of SAM. We treat such mechanisms as a source of error contributing to the uncertainty on our estimates of the step response functions.

It is also important to note that the CMIP5 ensemble members used in our analysis do not resolve eddies and rely on parameterizations to represent them. Therefore, these GCMs may be missing an important element of the ocean's response to winds. Böning et al. (2008) present observational evidence indicating that isopycnal slopes in the SO have not changed over the last few decades despite trends in the SAM. The Böning et al. (2008) results are consistent with the eddy compensation phenomenon and support the possibility that unresolved eddy processes can strongly modulate anomalies in the wind-driven circulation. Models that lack the ability to simulate realistic eddy compensation overestimate the magnitude of the anomalous residual upwelling under a poleward intensification of the westerlies. This may be a source of SO warming bias in the response of low-resolution GCMs to SAM. Despite this shortcoming of our study, we reiterate that it is important to understand how poleward intensifying westerlies impact the SO in the very same models that are widely used to analyze historical climate change and make future projections.

Finally, our analysis can be utilized to make a qualitative estimate for the SST response to SAM in the real SO. Our results suggest that during a sustained positive phase of the SAM, SO SSTs can exhibit a non-monotonic evolution. A strong and rapid transient cooling may be followed by a gradual recovery. However, our results do not suggest a high warming rate during the slow response to SAM.

Our results have implications for surface heat uptake in the real SO and for the persistent expansion of the sea ice cover around Antarctica. The positive SAM trend over the last decades may have allowed a cooler SO to absorb more excess heat from the atmosphere in a warming world. Furthermore, SAM-induced negative SST anomalies may have contributed to the observed increase in SO sea ice extent (Holland et al. 2016, in prep.; Kostov et al. 2016, in prep.). However, if the real SO exhibits a two-timescale response to SAM, the observed SST trends may eventually reverse sign. Hence a sustained poleward intensification of the westerly winds-due to ozone and greenhouse gas forcing-could eventually contribute to a surface warming of the SO, a decreased rate of heat uptake, and a reduction in sea ice concentration. It is therefore important to constrain both the short-term and the long-term SO SST response to SAM.

Acknowledgments The CMIP5 data for this study is available at the Earth System Grid Federation (ESGF) Portal (https://pcmdi9.1lnl.gov/ projects/esgf-1lnl/). Y.K. received support from an NSF MOBY Grant, award \#1048926. J.M., U.H., D.F., and M.M.H. were funded by the NSF FESD program, Grant Award \#1338814. K.C.A. was supported by a James McDonnell Foundation Postdoctoral Fellowship and NSF Grant OCE-1523641. We would like to thank the World Climate Research Programme and the Working Group on Coupled Modelling, which is in charge of CMIP5. We extend our appreciation to the organizations that support and develop the CMIP infrastructure: the US Department of Energy through its Program for Climate Model Diagnosis and Intercomparison and the Global Organization for Earth System Science Portals. We thank the CMIP5 climate modeling groups for providing their numerical output. We express gratitude to Paul O'Gorman, Jan Zika, and an anonymous reviewer for their helpful comments and suggestions. 


\section{Appendix: Verification of the methodology}

We test our methodology from Sect. 2 in order to ascertain its reliability. Our verification procedure involves applying the regression algorithm to systems with a known prescribed step response function. The latter is convolved with a randomly generated order 1 autoregressive timeseries (AR(1)) that is 1000 years long and resembles a SAM forcing. The result of the convolution is our synthetic SST response, which is strongly diluted with a different AR(1) process characterized by longer memory. We choose parameters for the AR(1) models such that their autocorrelations resemble those of SAM and SO SST timeseries in the CMIP5 GCMs (for instance, Fig. 10a, c). We conduct multiple verification tests with different choices of AR(1) parameters. We also vary the signal to noise ratio in our synthetic SST. Figure $10 \mathrm{~b}$ and $\mathrm{d}$ show examples from two different tests.

Within every test we generate an ensemble of multiple synthetic SAM and SST signals with the same statistical properties but different random values. We apply our algorithm separately to each realization in the same fashion as our analysis of CMIP5 control simulations. The verification tests confirm the validity of our method for estimating step response functions.
Fig. 10 Application of the regression algorithm to systems with a known prescribed step response function. On the top row we show a test case where we assume long memory in our SAM and SST signals. The SST signal is diluted such that $60 \%$ of the variance is noise. In a on the left, we show the lagged autocorrelations of SAM and SST in CCSM4 (gray dashed curves) and our synthetic artificially generated signals (solid black curves). In $\mathbf{b}$ we show applications of the regression algorithm. The thick black curve is the true prescribed step response function. The thin gray curves and the vertical bars denote the estimated step response function $S S T_{\text {Step }}(t)$ and the uncertainties $\sigma_{S S T s t e p}(t)$ produced by applying our regression algorithm. The two gray curves in panel $\mathbf{b}$ result from analyzing separate realizations in which we use the same prescribed step response and AR timeseries with the same statistical properties (illustrated in a) but different random values. On the bottom row we show a test case where we assume shorter memory in the SAM and SST signals, but the SST signal is diluted with more noise, such that the forced response contributes only $20 \%$ of the total variance. $\mathbf{c}, \mathbf{d}$ Are analogous to $\mathbf{a}, \mathbf{b}$
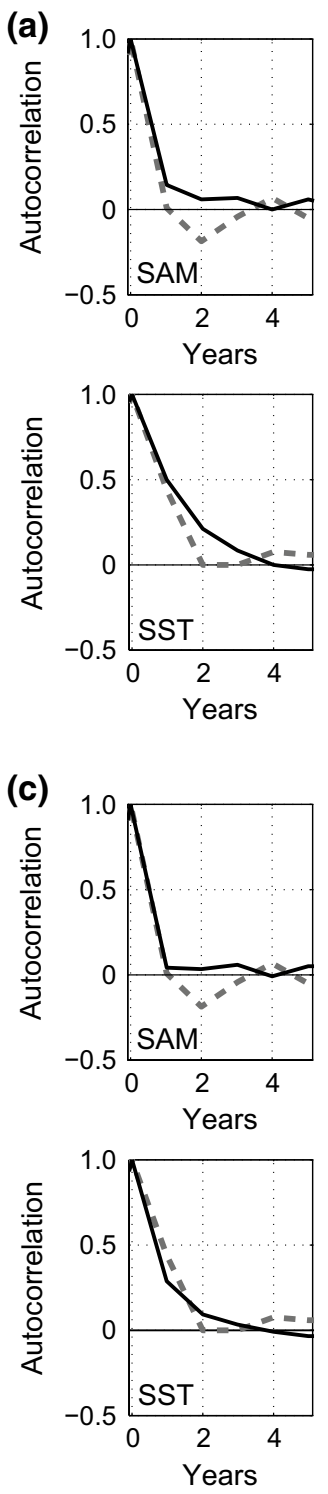

(b)

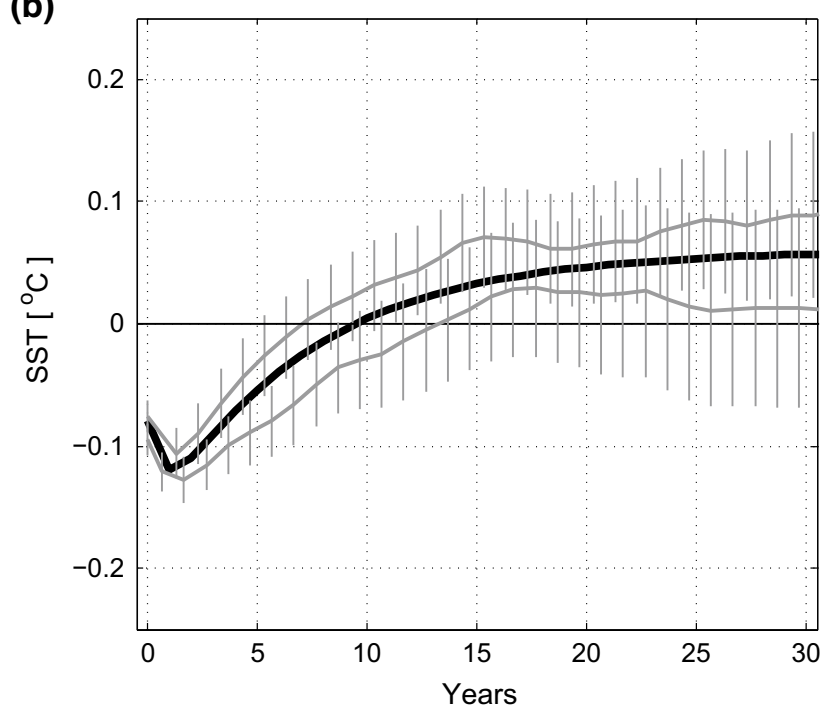

(d)

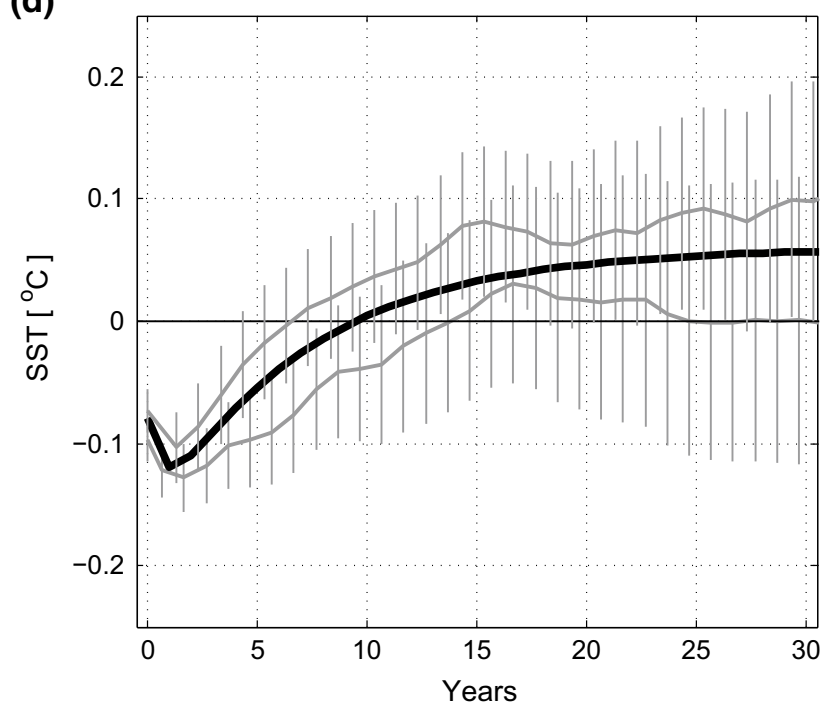




\section{References}

Armour KC, Bitz CM (2016) Observed and projected trends in Antarctic sea ice. US CLIVAR Var 13(4):13-19

Armour KC, Marshall J, Scott J, Donohoe A, Newsom ER (2016) Southern Ocean warming delayed by circumpolar upwelling and equatorward transport. Nat Geosc. doi:10.1038/ngeo2731

Bitz CM, Polvani LM (2012) Antarctic climate response to stratospheric ozone depletion in a fine resolution ocean climate model. Geophys Res Lett. doi:10.1029/2012GL053393

Böning CW, Dispert A, Visbeck M, Rintoul SR, Schwarzkopf FU (2008) The response of the Antarctic Circumpolar Current to recent climate change. Nat Geosci 1:864-869. doi:10.1038/ ngeo362

Ciasto LM, Thompson DWJ (2008) Observations of large scale ocean atmosphere interaction in the Southern Hemisphere. J Clim 21:1244-1259. doi:10.1175/2007JCLI1809.1

de Lavergne C, Palter JB, Galbraith ED, Bernardello R, Marinov I (2014) Cessation of deep convection in the open Southern Ocean under anthropogenic climate change. Nat Clim Change 4:278282. doi:10.1038/nclimate2132

DeAngelis AM, Qu X, Zelinka MD, Hall A (2015) An observational radiative constraint on hydrologic cycle intensification. Nature 528:249-253. doi:10.1038/nature 15770

Dee DP, Uppala SM, Simmons AJ et al (2011) The ERA-Interim reanalysis: configuration and performance of the data assimilation system. Q J R Meteorol Soc 137:553-597. doi:10.1002/qj.828

Fan T, Deser C, Schneider DP (2014) Recent Antarctic sea ice trends in the context of Southern Ocean surface climate variations since 1950. Geophys Res Lett 41:2419-2426. doi:10.1002/201 4GL059239

Ferreira D, Marshall J, Bitz CM, Solomon S, Plumb A (2015) Antarctic ocean and sea ice response to ozone depletion: a two-time-scale problem. J Clim 28:1206-1226. doi:10.1175/JCLI-D-14-00313.1

Fyfe JC, Saenko OA, Zickfeld K et al (2007) The role of poleward-intensifying winds on Southern Ocean warming. J Clim 20:5391-5400. doi:10.1175/2007JCLI1764.1

Gillett NP, Thompson DWJ (2003) Simulation of recent Southern Hemisphere climate change. Science 302:273-275. doi:10.1126/ science. 1087440

Good SA, Martin MJ, Rayner NA (2013) EN4: quality controlled ocean temperature and salinity profiles and monthly objective analyses with uncertainty estimates. J Geophys Res Oceans 118:6704-6716. doi:10.1002/2013JC009067

Hall A, Visbeck M (2002) Synchronous variability in the Southern Hemisphere atmosphere, sea ice, and ocean resulting from the Annular Mode. J Clim 15:3043-3057. doi:10.1175/15200442(2002) 015<3043:SVITSH >2.0.CO;2

Hasselmann K, Sausen R, Maier-Reimer E, Voss R (1993) On the cold start problem in transient simulations with coupled atmosphereocean models. Clim Dyn 9(2):53-61. doi:10.1007/BF00210008

Hausmann U, Czaja A, Marshall J (2016) Estimates of air-sea feedbacks on sea surface temperature anomalies in the Southern Ocean. J Clim 29:439-454. doi:10.1175/JCLI-D-15-0015.1

Hutchinson DK, England MH, Santoso A, Hogg AM (2013) Interhemispheric asymmetry in transient global warming: the role of Drake Passage. Geophys Res Lett 40:1587-1593. doi:10.1002/ grl.50341

Hutchinson DK, England MH, Hogg AMcC, Snow K (2015) Interhemispheric asymmetry of warming in an eddy permitting coupled sector model. J Clim 28:7385-7406. doi:10.1175/ JCLI-D-15-0014.1

Knutti R, Masson D, Gettelman A (2013) Climate model genealogy: generation CMIP5 and how we got there. Geophys Res Lett 40:1194-1199. doi:10.1002/grl.50256
Langlais C, Rintoul S, Zika J (2015) Sensitivity of Antarctic circumpolar transport and eddy activity to wind patterns in the Southern Ocean. J Phys Oceanogr 45:1051-1067. doi:10.1175/ JPO-D-14-0053.1

Marshall J, Armour KC, Scott JR, Kostov Y, Hausmann U, Ferreira D, Shepherd TG, Bitz CM (2014) The ocean's role in polar climate change: asymmetric Arctic and Antarctic responses to greenhouse gas and ozone forcing. Philos Trans R Soc A 372:20130040. doi:10.1098/rsta.2013.0040

Marshall J, Scott JR, Armour KC, Campin J-M, Kelley M, Romanou A (2015) The ocean's role in the transient response of climate to abrupt greenhouse gas forcing. Clim Dyn 44(7):2287-2299. doi:10.1007/s00382-014-2308-0

Meijers AJS (2014) The Southern Ocean in the Coupled Model Intercomparison Project phase 5. Philos Trans R Soc A 372:20130296. doi:10.1098/rsta.2013.0296

Oke P, England M (2004) Oceanic response to changes in the latitude of the Southern Hemisphere subpolar westerly winds. J Clim 17:1040-1054. doi:10.1175/1520-0442(2004)017<1040:ORTCI $\mathrm{T}>2.0 . \mathrm{CO} ; 2$

Purich A, Caj W, England MH, Cowan T (2016) Evidence for link between modelled trends in Antarctic sea ice and underestimated westerly wind changes. Nat Commun 7:10409. doi:10.1038/ ncomms 10409

Reynolds RW, Rayner NA, Smith TM, Stokes DC, Wang W (2002) An improved in situ and satellite SST analysis for climate. J Clim 15:1609-1625. doi:10.1175/1520-0442(2002) 015<1609:AIISA $\mathrm{S}>2.0 . \mathrm{CO} ; 2$

Russell JL, Dixon KW, Gnanadesikan A, Stouffer RJ, Toggweiler JR (2006) The Southern Hemisphere westerlies in a warming world: propping open the door to the deep ocean. J Clim 19:6382-6390. doi:10.1175/JCLI3984.1

Salleé J-B, Shuckburgh E, Bruneau N, Meijers AJS, Bracegirdle TJ, Wang Z (2013) Assessment of Southern Ocean mixed layer depths in CMIP5 models: historical bias and forcing response. J Geophys Res Oceans 118:1845-1862. doi:10.1002/jgrc.20157

Sen Gupta A, England M (2006) Coupled ocean-atmosphere-ice response to variations in the Southern Annular Mode. J Clim 19:4457-4486. doi:10.1175/JCLI3843.1

Sen Gupta A, England MH (2007) Coupled ocean-atmosphere feedback in the Southern Annular Mode. J Clim 20:3677-3692. doi:10.1175/JCLI4200.1

Sigmond M, Fyfe JC (2010) Has the ozone hole contributed to increased Antarctic sea ice extent? Geophys Res Lett 37:L18502. doi:10.1029/2010GL044301

Sigmond M, Fyfe JC (2014) The Antarctic sea ice response to the ozone hole in climate models. J Clim 27:1336-1342. doi:10.1175/JCLI-D-13-00590.1

Sigmond M, Reader MC, Fyfe JC, Gillett NP (2011) Drivers of past and future Southern Ocean change: stratospheric ozone versus greenhouse gas impacts. Geophys Res Lett. doi:10.1029/201 1GL047120

Solomon A, Polvani LM, Smith KL, Abernathey RP (2015) The impact of ozone depleting substances on the circulation, temperature, and salinity of the Southern Ocean: an attribution study with CESM1 (WACCM). Geophys Res Lett. doi:10.1002/2015GL064744

Taylor KE, Stouffer RJ, Meehl GA (2012) An overview of CMIP5 and the experiment design. Bull Am Meteorol Soc 93:485-498. doi:10.1175/BAMS-D-11-00094.1

Thomas JL, Waugh DW, Gnanadesikan A (2015) Southern Hemisphere extratropical circulation: recent trends and natural variability. Geophys Res Lett 42:5508-5515. doi:10.1002/2015GL064521

Thompson D, Solomon S (2002) Interpretation of recent Southern Hemisphere climate change. Science 296(5569):895-899. doi:10.1126/science. 1069270 
Thompson DWJ, Solomon S, Kushner PJ et al (2011) Signatures of the Antarctic ozone hole in Southern Hemisphere surface climate change. Nat Geosci 4:741-749. doi:10.1038/ngeo1296

Wang G, Cai W, Purich A (2014) Trends in Southern Hemisphere wind-driven circulation in CMIP5 models over the 21st century: ozone recovery versus greenhouse forcing. J Geophys Res Oceans 119:2974-2986. doi:10.1002/2013JC009589
Waugh DW, Primeau F, DeVries T, Holzer M (2013) Recent changes in the ventilation of the Southern Oceans. Science 339:568-570. doi:10.1126/science. 1225411

Waugh DW (2014) Changes in the ventilation of the southern oceans. Philos Trans R Soc A 372:20130269. doi:10.1098/rsta.2013.0269 